\title{
KEMAMPUAN KOMUNIKASI MATEMATIS BERDASARKAN GENDER MELALUI TUTOR SEBAYA DAN CTL
}

\author{
Amanda Syahri Nasution ${ }^{1 *}$, Ramadhani ${ }^{2 *}$, Rosmilan Pulungan ${ }^{3}$ \\ 1,2,3 Universitas Muslim Nusantara Al Washliyah \\ * Corresponding Author. Email: amandasyahri@umnaw.ac.id \\ Received: 26 Juni 2020: Revised: 15 September 2020 ; Accepted: 30 September 2020
}

\begin{abstract}
ABSTRAK
Kemampuan komunikasi matematis mahasiswa dapat berbeda berdasarkan model pembelajaran yang diterapkan. Model tutor sebaya dan CTL merupakan model yang dapat dijadikan alternatif untuk melihat perbedaan kemampuan komunikasi matematis mahasiswa. Perbedaan kemampuan yang dimiliki mahasiswa tersebut tidak hanya terlihat dari pemilihan model saja tetapi juga berdasarkan gender. Gender dapat menjadi tolak ukur untuk menentukan pemahaman komunikasi matematis. Penelitian bermaksud untuk melihat perbedaan pemahaman komunikasi matematis mahasiswa berdasarkan gender dan ada atau tidaknya hubungan tutor sebaya dan CTL serta gender pada pemahaman komunikasi matematis mahasiswa. Jenis penelitian ini adalah kuasi eksperiman dengan sampel penelitian melibatkan dua kelas. Kelas pertama menerapkan model tutor sebaya sedangkan kelas kedua menerapkan model CTL. Data penelitian berasal dari tes kemampuan komunikasi matematis mahasiswa. Analisis data penelitian berupa analisis deskriptif dan analisis inferensial dengan menggunakan Two-Way ANOVA. Penelitian membuktikan ada perbedaan pemahaman komunikasi matematis mahasiswa berdasarkan gender dan tidak ada hubungan tutor sebaya dan CTL serta gender pada pemahaman komunikasi matematis mahasiswa. Mahasiswa laki-laki lebih mampu mengkomunikasikan matematis secara tertulis dalam bentuk written text 52\% dan mathematical expression 54\% sedangkan mahasiswa perempuan lebih mampu dalam mengkomunikasikan secara drawing 55\%.
\end{abstract}

Kata Kunci: Komunikasi, Gender, Tutor Sebaya, CTL

\section{ABSTRACT}

Mathematical communication ability of collegers can differ based on the learning model applied. The peer teaching model and CTL are models that can be used as alternatives to see the differences in collegers' mathematical communication ability. The difference in the abilities of these students can not only be seen from the choice of models but also based on gender. Gender can be a benchmark for determining understanding of mathematical communication. The study intends to look at differences in understanding of collegers' mathematical communication based on gender and presence or absence a relationship of peer teaching and CTL with gender on understanding of collegers' mathematical communication. This type of research is a quasi experiment with the research sample involving two classes. The first class applies the peer teaching model while the second class applies the CTL model. The research data came from a test of collegers' mathematical communication skills. Analysis of research data in the form of descriptive analysis and inferential analysis using Two-Way ANOVA. Research proves that there are differences in collegers 'understanding of mathematical communication based on gender and there is no relationship between peer teaching and CTL with gender on collegers' understanding of mathematical communication. Male collegers are better able to communicate mathematical in written form in written text 52\% and mathematical expressions $54 \%$ while female collegers are better able to communicate in drawings $55 \%$.

Keywords: Communication, Gender, Peer Teaching, CTL

How to Cite: Nasution, A, H., Ramadhani \& Pulungan, R. (2020). Kemampuan Komunikasi Matematis Berdasarkan Gender Melalui Tutor Sebaya Dan CTL. Histogram: Jurnal Pendidikan Matematika, 4(2), $318 \quad-\quad 327, \quad$ doi: http://dx.doi.org/10.31100/histogram.v4i2.614

Permalink/DOI: http://dx.doi.org/10.31100/histogram.v4i2.614 


\section{Histogram: Jurnal Pendidikan Matematika, 4 (2), 2020 - 319 Amanda Syahri Nasution ${ }^{1 *}$, Ramadhani ${ }^{2}$, Rosmilan Pulungan ${ }^{3}$}

\section{PENDAHULUAN}

Komunikasi adalah kunci utama sebagai alat untuk menyampaikan ataupun mengemukakan pemikiran di antara perseorangan. Semakin baik perseorangan dalam berkomunikasi maka semakin baik pula hubungan satu sama lain. Secara ideal, komunikasi dapat menginformasikan pandangan seseorang menjadi persepektif bersama. Hal tersebut didukung (Umar, 2012) menyatakan jika seseorang di tengah masyarakat dapat berkomunikasi dengan baik maka akan lebih cepat baginya untuk beradaptasi dengan individu lain di lingkungan tersebut.

Komunikasi ternyata tidak hanya penting digunakan pada kehidupan sehari-hari tetapi juga pada dunia pendidikan. Proses belajar mengajar tidak terlepas dari komunikasi. Pendidik berkomunikasi secara lisan maupun tulisan untuk memaparkan materi pelajaran pada anak didik. Hal tersebut dilakukan pendidik sebagai upaya anak didik dapat memahami materi dari suatu mata pelajaran. (Purnama, I. L., \& Aldila, 2016) menyatakan bahwa melalui komunikasi maka siswa dapat mengekspoitasi pemikiran dari berbagai perspektif baik cara berfikir maupun tingkat pemahaman siswa dalam menorganisir pelajaran.

Peserta didik akan lebih mudah saling bertukar pikiran melalui komunikasi pada mata pelajaran non eksata tetapi lain halnya dengan mata pelajaran eksata. Eksata mengharuskan peserta didik untuk dapat memahami serta mengemukakan pendapat melalui komunikasi dengan mengubah simbol ke bentuk pernyataan ataupun kalimat. Begitupun sebaliknya, peserta didik harus dapat mengubah suatu pernyataan ke bentuk simbol ataupun representasi. Penelitian yang dilakukan (Hanna et al., 2017) menyatakan siswa akan lebih mudah memahami konsep pelajaran fisika jika dapat merepresentasikan soal ke dalam bentuk gambar dengan menemukan sendiri defenisi, fakta serta konsep berdasarkan pemahaman mereka sendiri.

(Saputro, 2014) memperoleh bahwa secara tradisonal siswa mengalami kesulitan untuk mengkomunikasikan pecahan baik secara representasi, simbolisasi maupun formalisasi diakibatkan kurangnya pemahaman konsep mengenai pecahan. Dengan kata lain, peserta didik secara akademik seharusnya dapat berkomunikasi baik pada materi eksata seperti matematika.

Mahasiswa pada jurusan matematika seharusnya terampil berkomunikasi secara matematis agar pembelajaran yang dilakukan berjalan dengan lancar. Komunikasi matematis tidak berbeda dengan komunikasi biasanya berupa lisan dan juga tulisan. Namun pada kenyataannya mahasiswa masih mengalami kesulitan dalam melakukan 


\section{Histogram: Jurnal Pendidikan Matematika, 4 (2), 2020 - 320 Amanda Syahri Nasution ${ }^{1 *}$, Ramadhani ${ }^{2}$, Rosmilan Pulungan ${ }^{3}$}

komunikasi matematis terutama secara tertulis. Kemampuan komunikasi yang dimiliki tiap mahasiswa berbeda-beda.

Kualifikasi komunikasi matematis penting bagi peserta didik baik dari tingkat SMP, SMA dan terutama Perguruan Tinggi karena merupakan inti dari belajar matematika. Asikin (Darkasyi et al., 2014) menyatakan bahwa pemahaman komunikasi matematis dimiliki pendidik serta anak didik harus saling terjalin dengan baik dikarenakan hal ini dapat mendukung lancarnya pembelajaran.

Peserta didik pada tingkat mahasiswa harus dapat berkomunikasi lebih baik daripada siswa. Komunikasi lisan dan tulisan tersebut merupakan indikator dari kemampuan komunikasi. LACOE (Ruswanto et al., 2018) berpendapat bahwa komunikasi matematis terdiri dari (1) menjelaskan gagasan secara matematis; (2) mengubah kalimat menjadi representasi matematis; (3) menganalisis serta mengevaluasi konsep matematis dan (4) mengaplikasikan konsep matematika menjadi asumsi serta dalih.

Greenes dan Schulman (McVarish, 2008) mengatakan bahwa secara spesifik komunikasi matematika dapat membantu siswa untuk berasumsi; menganalisis serta mendemonstrasikan data dalam bentuk skema, diagram ataupun gambar. Brenner (Siahaan \& Napitupulu, 2018) menyatakan bahwa kemampuan komunikasi matematis terbagi menjadi beberapa bagian meliputi: 1) mengekspresikan gagasan matematika menjadi model matematika, 2) mengubah kalimat menjadi bentuk representasi matematika dan 3) mendeskripsikan masalah matematika dengan bahasa singular serta memecahkan masalahnya.

Baroody (Rahmawati, 2013) juga mengemukakan ada lima indikator yang harus diperhatikan untuk melihat komunikasi matematis seperti menggambarkan, menelaah, memahami, membahas dan mendokumentasikan. Berdasarkan beberapa pendapat pakar tentang kriteria tersebut maka yang diamati terletak pada aspek writing dan representing (drawing and mathematical expression).

Kemampuan komunikasi yang dimiliki mahasiswa dapat berbeda berdasarkan tingkat kemampuan yang dimiliki serta gender yang menjadi faktor dalam menentukan tinggi rendahnya kemampuan tersebut. Gender laki-laki lebih unggul berkomunikasi secara lisan dibandingkan dengan perempuan yang lebih suka berkomunikasi secara tertulis. (Amri, 2009) menjelaskan bahwa siswa perempuan lebih akurat dalam menggunakan kata verbal maupun non verbal secara tertulis daripada siswa laki-laki. 


\section{Histogram: Jurnal Pendidikan Matematika, 4 (2), 2020 - 321 Amanda Syahri Nasution ${ }^{1 *}$, Ramadhani ${ }^{2}$, Rosmilan Pulungan ${ }^{3}$}

Selain gender, komunikasi matematis membutuhkan metode yang tepat untuk dapat meningkatkan pemahaman mahasiswa. Pendidik dapat membantu mahasiswa menjadi lebih unggul dengan menggunakan metode pembelajaran. Tutor sebaya dan CTL merupakan model pembelajaran yang dapat membantu proses pembelajaran. Tutor sebaya merupakan pembelajaran dimana melibatkan interaksi antar mahasiswa untuk saling berkomunikasi memahami serta menyelesaikan masalah secara matematis.

Suryo \& Amin (Suprijadi, 2015) mengemukakan tutor sebaya dapat dijadikan alternatif karena pada proses pembelajaran mahasiswa dapat saling membantu dengan memberikan masukan untuk memahami materi. Model ini diterapkan agar mahasiswa tidak canggung dalam memberikan masukan kepada temannya sehingga memotivasi diri memahami pelajaran.

CTL merupakan pembelajaran yang dilakukan dengan cara mengkomunikasikan materi secara lisan terkait dengan konteks nyata yang berada di lingkungan sekitar mahasiswa untuk mempermudah memahami menyelesaikan permasalahan matematika. Hal ini dipertegas oleh Blaachar (Trianto, 2009) mengatakan bahwa CTL merupakan model yang diterapkan oleh pengajar untuk memudahkan mahasiswa memahami pelajaran secara real. Dengan demikian, tutor sebaya dan CTL bermanfaat dalam meningkatkan dan mengembangkan kemampuan komunikasi matematis mahasiswa baik mahasiswa.

Berdasarkan pemaparan mengenai model tutor sebaya dan CTL maka peneliti tertarik untuk melihat perbedaan kemampuan komunikasi matematis mahasiswa diterapkan dengan model tersebut yang dilihat berdasarkan gender. Tujuan penelitian ini untuk melihat perbedaan kemampuan komunikasi matematis mahasiswa laki-laki dan mahasiswa perempuan berdasarkan indikator kemampuan dengan membandingkan kemampuan melalui penerapan model yang berbeda.

\section{METODE PENELITIAN}

Penelitian ini termasuk quasi experiment dengan maksud untuk melihat perbedaan pemahaman komunikasi matematika antara mahasiswa berdasarkan gender. Variabel penelitian ini terdiri dari dinamis dan statis. Variabel dinamis penelitian adalah kemampuan komunikasi matematis sedangkan variabel statis penelitian adalah gender.

Populasi penelitian ini melibatkan seluruh mahasiswa pendidikan matematika Universitas Muslim Nusantara Al Washliyah. Sampel penelitian melibatkan dua kelas semester 5 dengan kelas pertama menerapkan model turor sebaya sedangkan kelas kedua menerapkan model CTL. 


\section{Histogram: Jurnal Pendidikan Matematika, 4 (2), 2020 - 322 Amanda Syahri Nasution ${ }^{*}$, Ramadhani ${ }^{2}$, Rosmilan Pulungan ${ }^{3}$}

Penelitian ini dirancang untuk membandingkan pemahaman komunikasi matematika mahasiswa berdasarkan gender dengan menggunakan model tutor sebaya. Instrumen tes pada penelitian sebelum diimplementasikan maka sebaiknya diujicobakan. Desain penelitian ini adalah sebagai berikut:

Tabel 1. Desain Penelitian

\begin{tabular}{|c|c|c|c|}
\hline \multicolumn{2}{|c|}{ Kemampuan yang diukur } & \multicolumn{2}{|c|}{$\begin{array}{c}\text { Kemampuan Komunikasi } \\
\text { Matematis } \\
\text { (A) }\end{array}$} \\
\hline \multicolumn{2}{|c|}{ Pembelajaran } & $\begin{array}{l}\text { Tutor Sebaya } \\
\text { (B) }\end{array}$ & $\begin{array}{l}\text { CTL } \\
\text { (C) }\end{array}$ \\
\hline \multirow[t]{2}{*}{ Gender } & $\begin{array}{l}\text { Laki-Laki } \\
\text { (L) }\end{array}$ & ALB & ALC \\
\hline & $\begin{array}{l}\text { Perempuan } \\
\text { (P) }\end{array}$ & APB & APC \\
\hline
\end{tabular}

Keterangan:

ALB : Kemampuan komunikasi matematis mahasiswa laki-laki melalui tutor sebaya

APB : Kemampuan komunikasi matematis mahasiswa perempuan melalui tutor sebaya

ALC : Kemampuan komunikasi matematis mahasiswa laki-laki melalui CTL

APC : Kemampuan komunikasi matematis mahasiswa perempuan melalui CTL

Sebelum melaksanakan penelitian, terlebih dahulu instrumen diujikan terlebih dahulu supaya valid dan reliabel sehingga data perangkat penelitian akurat. Setelah instrumen valid dan reliabel maka dapat dilaksanakan penelitian untuk mengumpulkan data. Selain itu, data yang dikumpulkan juga harus normal dan homogen. Penelitian ini diuraikan secara deskriptif serta inferensial. Analisis deskriptif terdiri dari mean, varian, standar deviasi, skor terendah dan tertinggi sedangkan analisis inferensial dengan menggunakan Two-Way ANOVA berbantuan SPSS versi 22.

\section{HASIL DAN PEMBAHASAN}

\section{A. Hasil Penelitian}

Pemaparan deskripsi hasil analisis pemahaman komunikasi matematika mahasiswa berdasarkan gender yaitu:

Tabel 2. Perhitungan Statistik Tutor Sebaya dan CTL Terhadap Pemahaman Komunikasi Matematika Mahasiswa

\begin{tabular}{|c|c|c|c|c|c|c|}
\hline \multirow[b]{2}{*}{ Kemampuan } & \multirow[b]{2}{*}{ Model } & \multicolumn{5}{|c|}{ Statistik } \\
\hline & & Mean & Varian & $\begin{array}{c}\text { Standar } \\
\text { Deviasi }\end{array}$ & Minimum & Maksimum \\
\hline $\begin{array}{c}\text { Komunikasi } \\
\text { Matematis }\end{array}$ & $\begin{array}{l}\text { Tutor } \\
\text { Sebaya }\end{array}$ & 29,91 & 54,658 & 7,393 & 18 & 43 \\
\hline
\end{tabular}


Histogram: Jurnal Pendidikan Matematika, 4 (2), 2020 - 323

Amanda Syahri Nasution ${ }^{1 *}$, Ramadhani ${ }^{2}$, Rosmilan Pulungan ${ }^{3}$

\begin{tabular}{lcccccc}
\hline \multirow{2}{*}{ Kemampuan } & Model & \multicolumn{5}{c}{ Statistik } \\
\cline { 2 - 7 } & Mean & Varian & $\begin{array}{c}\text { Standar } \\
\text { Deviasi }\end{array}$ & Minimum & Maksimum \\
\cline { 2 - 7 } & CTL & 24,55 & 55,498 & 7,450 & 10 & 42 \\
\hline
\end{tabular}

(Sumber: Data Primer, Tahun: 2020)

Berdasarkan Tabel 2 menunjukkan bahwa skor minimum dan maksimum pemahaman komunikasi matematika mahasiswa melalui tutor sebaya adalah 18 dan 43 . Pemahaman komunikasi matematis mahasiswa gender laki-laki diperoleh skor minimum $40 \%$ sedangkan mahasiswa gender perempuan 51\%. Skor minimum pemahaman komunikasi matematika mahasiswa melalui CTL adalah 10 dan skor maksimumnya adalah 42 dengan pemahaman mahasiswa gender laki-laki 35\% sedangkan mahasiswa gender perempuan $47 \%$. Dengan demikian, terbukti pemahaman komunikasi matematika mahasiswa gender laki-laki lebih mahir daripada pemahaman mahasiswa gender perempuan.

Kemampuan berkomunikasi mahasiswa tidak hanya dilihat secara umum tetapi juga berdasarkan indikator. Kemampuan komunikasi yang dilihat pada penelitian adalah komunikasi secara tertulis. Adapun indikator yang dilihat adalah written text, drawing dan mathematical expression. Berdasarkan hasil penelitian dari segi indikator tersebut pemahaman mahasiswa gender laki-laki lebih mahir daripada mahasiswa gender perempuan. Adapun rekapitulasi pemahaman tersebut dapat diamati pada tabel berikut:

Tabel 3. Rekapitulasi Persentase Pemahaman Mahasiswa Berdasarkan Indikator Kemampuan Komunikasi Matematis Melalui Model Tutor Sebaya dan CTL

\begin{tabular}{lccccccc}
\hline $\begin{array}{l}\text { Indikator Kemampuan } \\
\text { Komunikasi Matematis }\end{array}$ & $\begin{array}{c}\text { Written Text } \\
\mathbf{( \% )}\end{array}$ & \multicolumn{2}{c}{$\begin{array}{c}\text { Drawing } \\
\mathbf{( \% )}\end{array}$} & \multicolumn{3}{c}{$\begin{array}{c}\text { Mathematical } \\
\text { Expression } \\
(\%)\end{array}$} \\
\hline \multirow{2}{*}{ Model } & $\begin{array}{c}\text { Tutor } \\
\text { Sebaya }\end{array}$ & CTL & $\begin{array}{c}\text { Tutor } \\
\text { Sebaya }\end{array}$ & CTL & \multicolumn{2}{c}{$\begin{array}{c}\text { Tutor } \\
\text { Sebaya }\end{array}$} & CTL \\
\hline \multirow{2}{*}{ Gender } & Laki-Laki & 52 & 46 & 45 & 30 & 54 & 48 \\
\cline { 2 - 9 } & Perempuan & 48 & 35 & 55 & 47 & 46 & 36 \\
\hline
\end{tabular}

(Sumber: Data Primer, Tahun: 2020)

Hasil persentase di atas menunjukkan pemahaman komunikasi matematika mahasiswa gender laki-laki lebih mahir pada indikator written text dan mathematical expression sedangkan mahasiswa perempuan lebih mahir pada indikator drawing. Dalam hal ini, mahasiswa perempuan lebih mahir menyatakan ide matematis melalui bentuk gambar sedangkan mahasiswa laki-laki lebih mahir berkomunikasi dengan menyatakan serta menjelaskan objek atau model matematis dalam bentuk ide matematis dan simbol. 


\section{Histogram: Jurnal Pendidikan Matematika, 4 (2), 2020 - 324 Amanda Syahri Nasution ${ }^{1 *}$, Ramadhani ${ }^{2}$, Rosmilan Pulungan ${ }^{3}$}

Hasil pengujian hipotesis penelitian menemukan ada perbedaan kemampuan komunikasi matematis mahasiswa berdasarkan gender melalui model tutor sebaya dan CTL dapat diamati pada tabel 4 berikut:

Tabel 4. Perhitungan Uji Anava Dua Jalur

\begin{tabular}{cccccc}
\hline Sumber Varian & JK & df & RJK & F & Sig. \\
\hline Model & 192,364 & 1 & 192,364 & 6,765 & 0,013 \\
Gender & 1911,364 & 1 & 1911,364 & 67,215 & 0,000 \\
Model*Gender & 61,455 & 1 & 61,455 & 2,161 & 0,149 \\
\hline
\end{tabular}

(Sumber: Data Primer, Tahun: 2020)

Berdasarkan perhitungan menggunkana bantuan SPSS versi 22 ditemukan perbedaan pemahaman komunikasi matematika mahasiswa berdasarkan gender dengan sig. model dan gender $<0,005$ yaitu 0,013 dan 0,000 dan tidaknya ditemukannya hubungan tutor sebaya dan CTL serta gender pada pemahaman komunikasi matematika mahasiswa terlihat dari sig. model $*$ gender $>0,005$ yaitu 0,149 .

\section{B. Pembahasan}

Kemampuan komunikasi matematis wajib bagi mahasiswa agar dapat mengemukakan konsep matematika secara verbal dan non verbal. Kemampuan dapat meningkat tergantung dengan model pembelajaran yang diterapkan pendidik. Komunikasi matematika perlu diterapkan karena disamping sebagai sarana memperdalam pemahaman konsep untuk memecahkan permasalahan matematis serta memberikan argumen selain itu dapat dijadikan sebagai cara untuk mengemukakan pikiran secara efisien (Yuniarti, 2014). (Rizqi, 2016) menyatakan kemampuan komunikasi matematis dapat berkembang dengan menerapkan model blended learning berlandaskan pemecahan masalah terkait dengan kehidupan nyata.

Model tutor sebaya dan CTL mempunyai kriteria untuk dapat meningkatkan serta mengembangkan kemampuan komunikasi matematis. Selain itu, model tersebut dapat memacu interaksi antara sesama mahasiswa dalam bertukar gagasan atau ide dengan membahas masalah matematis secara nyata. (Hodiyanto, 2017) menyatakan pembelajaran yang dilakukan melalui diskusi dalam menyelesaikan permasalahan secara konteks dapat merangsang pemahaman komunikasi matematika. (Rahmalia et al., 2019) menyatakan bahwa snowball throwing dan tutor sebaya berguna untuk peningkatan pemahaman komunikasi matematika.

Selain metode, ternyata gender terbukti berperan dalam meningkat atau tidak meningkatnya pemahaman komunikasi matematis mahasiswa. Meskipun, tidak semua 


\section{Histogram: Jurnal Pendidikan Matematika, 4 (2), 2020 - 325 Amanda Syahri Nasution ${ }^{1 *}$, Ramadhani' ${ }^{2}$, Rosmilan Pulungan ${ }^{3}$}

kemampuan dapat dipengaruhi oleh faktor gender tetapi untuk komunikasi ini memberikan peranan yang penting dalam meningkatkan kemampuan komunikasi mahasiswa. (Wijaya et al., 2016) menyatakan bahwa gender mempengaruhi tingkat komunikasi matematis siswa dimana siswa laki-laki lebih unggul berkomunikasi secara lisan sedangkan siswa perempuan secara tulisan. (Nugraha \& Pujiastuti, 2019) juga mengemukakan kemampuan komunikasi matematis dapat berbeda tergantung dengan gender terbukti dengan anak laki-laki lebih menguasai pemahaman matematis daripada anak perempuan.

Sejalan pemaparan di atas, penelitian membuktikan pemahaman mahasiswa gender laki-laki dalam berkomunikasi secara matematis lebih mahir daripada mahasiswa gender perempuan ditinjau secara universal maupun perspektif. Mahasiswa laki-laki dapat mengemukakan gagasan ataupun ide pemikiran yang lebih unggul daripada mahasiswa perempuan. Gender laki-laki maupun perempuan memiliki kelebihan masing-masing saat berkomunikasi verbal non verbal. Faktor yang menentukan berkembang atau tidaknya kemampuan komunikasi matematis mahasiswa tidak terlepas dari penerapan model yang dipilih pendidik. Model tutor sebaya dan CTL memberikan kontribusi dalam meningkatkan kemampuan komunikasi. Namun, diantara kedua model tersebut ternyata model tutor sebaya lebih efektif untuk meningkatkan serta mengembangkan kemampuan komunikasi matematis terutama pada mahasiswa laki-laki.

\section{KESIMPULAN DAN SARAN}

\section{A. Kesimpulan}

Penemuan membuktikan ada perbedaan pemahaman komunikasi mahasiswa berdasarkan gender dan tidak adanya hubungan tutor sebaya dan CTL serta gender dengan pemahaman komunikasi matematika mahasiswa. Pemahaman mahasiswa berkomunikasi dalam mengemukakan konsep matematika untuk gender laki-laki lebih unggul daripada gender perempuan dengan perbedaannya $0,7 \%$ melalui tutor sebaya dan CTL perbedaannya $1,4 \%$. Model tutor sebaya lebih efektif untuk diterapkan dalam meningkatkan komunikasi matematis pada mahasiswa berdasarkan gender daripada CTL.

\section{B. Saran}

Untuk para pendidik baik guru maupun dosen jika ingin melihat kemampuan komunikasi matematis tidak hanya secara umum tetapi lebih spesifik berdasarkan indikatornya agar lebih terlihat mana indikator yang menjadi faktor paling besar dalam 


\section{Histogram: Jurnal Pendidikan Matematika, 4 (2), 2020 - 326 Amanda Syahri Nasution ${ }^{1 *}$, Ramadhani ${ }^{2}$, Rosmilan Pulungan ${ }^{3}$}

mendukung kemampuan serta memilih model yang sesuai untuk diterapkan pada pembelajaran.

\section{DAFTAR PUSTAKA}

Amri, Z. (2009). Perbedaan bahasa siswa laki-laki dan siswa perempuan: sebuah studi kasus di kelas v sdn 09 air tawar barat padang sumatera barat. Lingua Didaktika: Jurnal Bahasa Dan Pembelajaran Bahasa, 3(1), 96-110.

Darkasyi, M., Johar, R., \& Ahmad, A. (2014). Peningkatan Kemampuan Komunikasi Matematis Dan Motivasi Siswa Dengan Pembelajaran Pendekatan Quantum Learning Pada Siswa SMP Negeri 5 Lhokseumawe. Jurnal Didaktik Matematika, $1(1), 21-34$.

Hanna, D., Sutarto, S., \& Harijanto, A. (2017). Model Pembelajaran Tema Konsep Disertai Media Gambar Pada Pembelajaran Fisika Di SMA. Jurnal Pembelajaran Fisika, 5(1), 23-29.

Hodiyanto, H. (2017). Kemampuan Komunikasi Matematis Dalam Pembelajaran Matematika. AdMathEdu, 7(1), 9-18.

McVarish, J. (2008). Where's the Wonder in Elementary Math? Encouraging Mathematical Reasoning in the Calssroom. Taylor \& Francis Group.

Nugraha, T. H., \& Pujiastuti, H. (2019). AnalisisKemampuan Komunikasi MatematisSiswa Berdasarkan Perbedaan Gender. Edumatica, 9(1), 1-7.

Purnama, I. L., \& Aldila, E. (2016). Kemampuan komunikasi matematis siswa ditinjau melalui model pembelajaran kooperatif tipe complete sentence dan team quiz. Jurnal Pendidikan Matematika Sriwijaya, 10(1), 26-41.

Rahmalia, Y., Sunismi, S., \& El Walida, S. (2019). Penerapan Model Kooperatif Tipe Snowball Throwing Dan Tutor Sebaya Untuk Meningkatkan Kemampuan Komunikasi Matematis Dan Keaktivan Belajar Siswa Kelas VIII. Jurnal Penelitian, Pendidikan, Dan Pembelajaran, 14(7), 50-56.

Rahmawati, F. (2013). Pengaruh Pendekatan Pendidikan Realistik Matematika dalam Meningkatkan Kemampuan Komunikasi Matematis Siswa Sekolah Dasar. SEMIRATA 2013, 225-238.

Rizqi, A. (2016). Kemampuan Komunikasi Matematis Siswa melalui Blended Learning Berbasis Pemecahan Masalah. PRISMA, Prosiding Seminar Nasional Matematika, 191-202.

Ruswanto, R., Dwijanto, D., \& Widowati, W. (2018). a Realistic Mathematics Education Model Includes Characteristic to Improve the Skill of Communication Mathematic. Unnes Journal of Mathematics Education Research, 7(1), 94-101.

Saputro, B. A. (2014). Kemampuan Komunikasi Matematis Siswa Sekolah Dasar Yang Belajar Menggunakan Permainan Tradisional. Metodik Didaktik: Jurnal Pendidikan $\mathrm{Ke}-\mathrm{SD}-\mathrm{An}, 10(2), 56-65$.

Siahaan, M. M. L., \& Napitupulu, E. E. (2018). The Difference of Students' Mathematical Communication Ability Taught by Cooperative Learning Model Think Talk Write Type and Numbered Head Together Type. Scholaria: Jurnal Pendidikan Dan Kebudayaan, 8(3), 231-242.

Suprijadi, D. (2015). Pengaruh Tutor Sebaya Terhadaap Hasil Belajar Matematika Siswa Kelas VII Smp Daarussalaam Jakarta. Faktor Exacta, 3(2), 127-135.

Trianto. (2009). Mendesain Model Pembelajaran Inovatif Progresif. Kencana Prenada Media Grup.

Umar, W. (2012). Membangun Kemampuan Komunikasi Matematis Dalam Pembelajaran 
Histogram: Jurnal Pendidikan Matematika, 4 (2), 2020 - 327

Amanda Syahri Nasution ${ }^{1 *}$, Ramadhani ${ }^{2}$, Rosmilan Pulungan ${ }^{3}$

Matematika. Infinity Journal, 1(1), 1-9.

Wijaya, I., Putra, H., Sujadi, I., \& Riyadi, R. (2016). Kemampuan Komunikasi Matematis Siswa Sesuai dengan Gender Dalam Pemecahan Masalah Pada Materi Balok Dan Kubus (Studi Kasus Pada Siswa SMP Kelas VIII SMP Islam Al-Azhar 29 Semarang). Universitas Sebelas Maret.

Yuniarti, Y. (2014). Pengembangan Kemampuan Komunikasi Matematis Dalam Pembelajaran Matematika Di Sekolah Dasar. EduHumaniora| Jurnal Pendidikan Dasar Kampus Cibiru, 6(2), 109-114. 